\title{
SPATIAL STATISTICS OF POULTRY PRODUCTION IN ANAMBRA STATE OF NIGERIA: A PRELIMINARY FOR BIO-ENERGY PLANT LOCATION MODELLING
}

\author{
E. C. Chukwuma ${ }^{1,}{ }^{*}$, L. C. Orakwe ${ }^{2}$, D. C. Anizoba ${ }^{3}$ and A. I. Manumehe ${ }^{4}$ \\ 1,2,3 DEPT. OF AGRIC. \& BIORESOURCES ENGINEERING NNAMDi AZIKIWE UNIVERSITY, AWKA, ANAMBRA STATE, NIGERIA \\ 4 NAtional Environmental Standards \& Regulations Enforcement AgEncy, AWKa, ANAmbra State, NigERIA \\ E-mail addresses:1 ecchukwuma@yahoo.com,2louiemeka@yahoo.com,3dananizoba@gmail.com, \\ ${ }^{4}$ mica4baby@yahoo.co.uk
}

\begin{abstract}
Consequent on the need to utilize bio-wastes for energy generation, a preliminary study for bio-energy plant location modelling was carried out in this work using spatial statistics technique in Anambra State of Nigeria as a case study. Spatial statistics toolbox in ArcGIS was used to generate point density map which reveal the regional patterns of biomass distribution and to generate hotspot analysis of zones of poultry production sites in the study area. The result of the study indicates that the central regions of the state is characterised with high point density poultry production sites, some of the locations with high point density poultry production values include: Ogbaru town which has the highest point density value of above $4,362,480 \mathrm{~kg}$ of poultry droppings. This is followed by Umuchu, Onitsha, Nise, Nibo and Amawbia, with point density value that ranges from 2,210,250kg to 4,362,480kg. Several hotspots were identified in the central region of the study area, and in the South west region of the study area (where Umuodu, Ogbakuba and Ossomala were located), while the Southern region of the study area is characterized with several coldspots. The hotspots zones and high point density production sites identified in this study should serve as suitable locations for siting bio-energy plants in the study area.
\end{abstract}

Key Word: Spatial Statistics, Poultry Production, Bio-energy Plant, Livestock Waste, Anambra State.

\section{INTRODUCTION}

With the rapid advancement of computer-based techniques for exploring, visualizing, and analyzing spatial features, it has become expedient that proper site suitability analysis should be undertaking using GIS technology in plant siting location decisions. Research indicates that certain areas are more prone to higher concentrations of biomass[1, 2,3].Such areas are widely labelled as 'hot spots', and are often targets for siting bio-energy plants for electric power generation and utilization [4, 5]. Since biomass resources are essentially transported from certain points of generation to processing point, the identification of hot spots would be helpful in reduction of transportation cost and hence production cost.

Spatial Statistics is a method of analyzing spatial distributions, patterns, processes, and relationships. While there may be similarities between spatial and non-spatial (traditional) statistics in terms of concepts and objectives, spatial statistics are unique in that they were developed specifically for use with geographic data. Unlike traditional non-spatial statistical methods, they incorporate space (proximity, area, connectivity, and/or other spatial relationships) directly into their mathematics. Spatial statistics also helps to determine if features are random, clustered, or evenly dispersed across any study area such as biomass generating sites. It helps in making decisions with higher level of confidence. Spatial statistics comprises of a set of techniques for describing and modeling spatial data. In many ways they extend what the mind and eyes do, intuitively, to assess spatial patterns, distributions, trends, processes and relationships. Spatial statistical techniques actually use space - area, length, proximity, orientation, or spatial relationships - directly in their mathematics [6]. 
Spatial statistics method has been used for various purposes such as groundwater potential quality mapping and determination of spatial distribution of major and minor ions present in the water and has been applied also in diversified applications in medical diagnosis, geology and other fields. Maps generated are used as preliminary screening tools for policy and decision-making in groundwater management strategies on a regional scale [7].

Höhn et al., [5] used spatial statistics to generate kernel density maps to point out the regional patterns of biomass distribution in Southern Finland, the researchers also used hotspot analysis to identify areas with high availability of agricultural resources in the study area which were located majorly in the rural areas. Based on these preliminary spatial analyses, the suitable candidate sites for bio-energy plant were derived by the researchers. Hence the objective of this study is to use spatial statistics to generate maps that could be used as preliminary screening tools for decision-making in location modelling of bio-energy plants in the study area.

\section{MATERIALS AND METHODOLOGY}

\subsection{The Study Area}

Anambra State is one of the 36 states of Nigeria, and is located in the South East geopolitical zone of Nigeria. Anambra State occupies a land mass of about 4,844 square kilometre and is bounded in the East by Enugu State, in the North by Kogi State, in the South by Rivers and Imo States, and in the West by Delta State. The national population census of 2006 gave the population of the State as 4.06 million with a population density of 1,500 to 2,000 persons living within every square kilometer. The State is divided into 21 local government areas with Awka serving as its state capital. It has equatorial type of climate with two main seasons viz: the rainy season which is often characterized by heavy storm and lasts from April to October and dry season that last from November to March. Figure 1 below shows map of Nigeria, and the study area in hash mark.

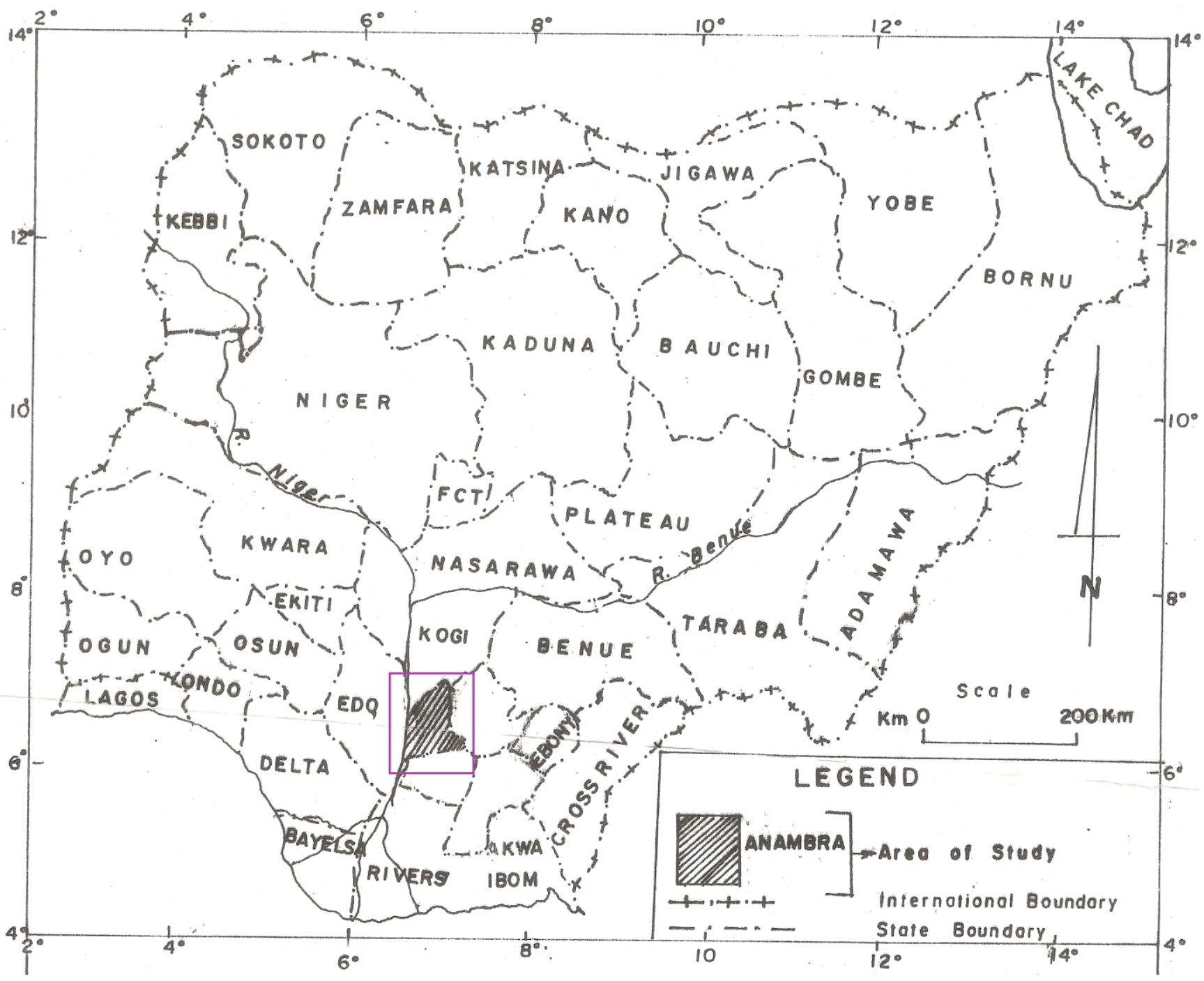

Figure 1: Map of Nigeria showing Anambra State. 


\subsection{Data Collection, Processing and Analysis}

Data of poultry production in the State was collected from Veterinary Department, Anambra State Ministry of Agriculture and Rural Development Awka. Estimates of the manure excreted by 1000 birds per day (based on average daily live weights during the birds' production cycle) are approximately $120 \mathrm{~kg}$ for layer chickens, $80 \mathrm{~kg}$ for meat chickens, 200 to $350 \mathrm{~kg}$ for turkeys (grower females and grower heavy males, respectively), and $150 \mathrm{~kg}$ for ducks [8]. Extrapolations were calculated to give general estimates for the manure generated with the corresponding number of birds for the various farm in the state. About 2000 poultry sites located in the state were analysed. The data of the yearly bio-wastes generated in various towns and villages of the study area and the geographical coordinate point is shown in the Appendix. Global Positioning System (GPS) receiver was used in field survey to determine the geographical co-ordinate of these poultry farms for data analysis in the study. The Spatial Statistics toolbox in ArcGIS version 10 was leveraged on in spatial analysis and operations in the study. The spatial statistics used in this study are outlined below:

\subsection{Spatial Autocorrelation Analyses}

CMRC [9] study indicated that a good approach for detecting hot spots is tests of spatial autocorrelation. Moran's I is a commonly used indicator of spatial autocorrelation. In this study, global Moran's I [10] was used as the first measure of spatial autocorrelation. Its values range from -1 to 1 . The value " 1 " means perfect positive spatial autocorrelation (high values or low values cluster together), while " -1 " suggests perfect negative spatial autocorrelation (a checkerboard pattern), and "0" implies perfect spatial randomness [11].

\subsection{Global Moran I}

This is the first approach in spatial auto correction, global calculations identifies the overall patterns or trends in the data. These types of statistics are very effective when there is a lot of complex data, and the interest is in understanding broad, overall trends. They work by comparing feature locations and/or attributes to a theoretical random distribution in order to determine statistically significant clustering or dispersion [12]. The global Moral I is given by the mathematical model below (eq. 1):

$$
I=\sum_{i}^{n} \sum_{j}^{n} W_{i j}\left(X_{i}-\dot{X}\right) /\left(S^{2} \sum_{i}^{n} \sum_{j}^{n} W_{i j}\right)
$$

In (1), the numerator is the covariance term with $i$ and $\mathrm{j}$ (two areal units), $\mathrm{x}$ is the data value in each unit, $\dot{\mathrm{X}}$ the overall value of $x$, and $W_{i j}$ is the proximity of location between point $i$ and $j$. By calculating the product of the unit's differences from $x$, the extent to which they vary together is determined. The product is positive, if both $x_{i}$ and $x_{j}$ lie on the same side (above or below) of the mean. It is negative, if the sides they are positioned are different, and the value depends on the difference from the overall value to the unit's values. These covariance terms are multiplied with $\mathrm{W}_{\mathrm{ij}}$ which switches each possible covariance on or off depending on

$$
s^{2}=\frac{1}{n} \sum_{i}^{n}\left(X_{i}-\dot{X}\right)^{2}
$$

\subsection{Local Moran I}

The other type of statistics tools used in analyzing patterns are categorized as Local Calculations. These calculations identify the extent and locations of clustering. The Local Moran's I index [11] can be expressed as:

$$
(x+a)^{n}=\frac{z_{i}-\hat{\mathrm{z}}}{\mathrm{o}^{2}} \sum_{j=0, j \neq i}^{n}\left[\mathrm{~W}_{\mathrm{ij}}\left(\mathrm{z}_{\mathrm{j}}-\hat{\mathrm{z}}\right)\right]
$$

Where $\hat{z}$ is the mean value of $z$ with the sample number of $n ; z_{j}$ is the value of the variable at location $i$; $z_{j}$ is the value at other locations (where $j \neq i$ ) $o^{2}$ is the variance of $\mathrm{z}$; and $\mathrm{W}_{\mathrm{ij}}$ is a distance weighting between $z_{i}$ and $z_{\mathrm{j}}$, which can be defined as the inverse of the distance. The weight $\mathrm{W}_{\mathrm{ij}}$ can also be determined using a distance band: samples within a distance band are given the same weight, while those outside the distance band are given the weight of 0 [12].

\subsection{Hot Spot Spatial Statistic Analysis}

One of the tools in the Mapping Clusters toolset is called the Hot Spot Analysis Getis Ord Gi* statistic, and it can be used to delineate clusters of features with values significantly higher or lower than the overall study areas mean or average value. This tool identifies clustering in both the high and the low attribute values. A standardized $\mathrm{Z}$ score is calculated for each feature. A high $\mathrm{Z}$ score results when a feature has a high value and it is surrounded by other features with high values. This is a hot spot. Similarly, a low Z score results when we have features with low values 
surrounded by other features with low values [12]. This is a cold spot. Getis-ord local statistic is given as:

$$
\begin{gathered}
G=\frac{\sum_{j=1}^{n} w_{i j} x_{j}-\dot{\mathrm{X}} \sum_{j=1}^{n} w_{i j}}{\sqrt[s]{\frac{\left[n \sum_{j=1}^{n} w^{2}{ }_{i j}-\left(\sum_{j=1}^{n} w_{i j}\right)^{2}\right]}{n-1}}} \\
\dot{X}=\frac{\sum_{j=1}^{n} x_{j}}{n} \\
s=\sqrt{\frac{\sum_{j=1}^{n} x^{2}{ }_{j}}{n}-(\dot{\mathrm{X}})^{2}}
\end{gathered}
$$

The result of the hot spot and cold spot analysis is shown in Figure 4.

\section{RESULT AND DISCUSSION}

One of the basics for regional analysis of biogas potential density in the study area is on the poultry production potential and density. Figure 2 below shows poultry production towns and villages in the State. From the Figure below, Anambra West L.G. A has no poultry production site; this has been attributed to the swampy nature of the terrain.

Hence, such a region is eliminated in the study area for siting biogas plant. Ayamelum L.G.A has only three poultry production sites, which include Anaku, Omor and Ifite-Ogwari (Located at far North of the study area). The central regions of the state is characterised with high density poultry production. Clustering of poultry production sites within a region is an indicator of higher biomass availability/accessibility and consequently sites suitable for location of bio-energy plants.

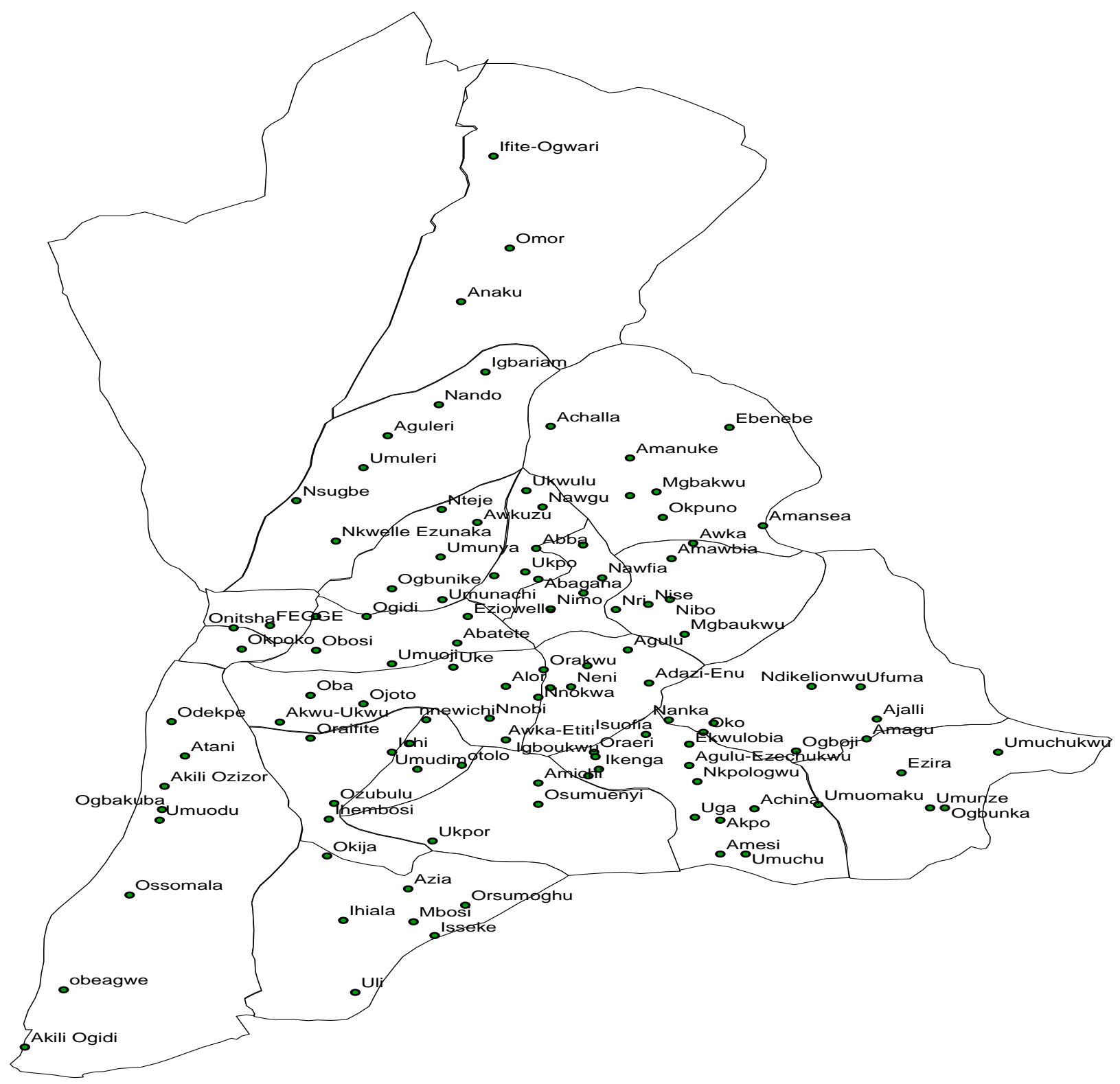

Figure 2: Shapefile of Poultry birds Producing areas of Anambra State 


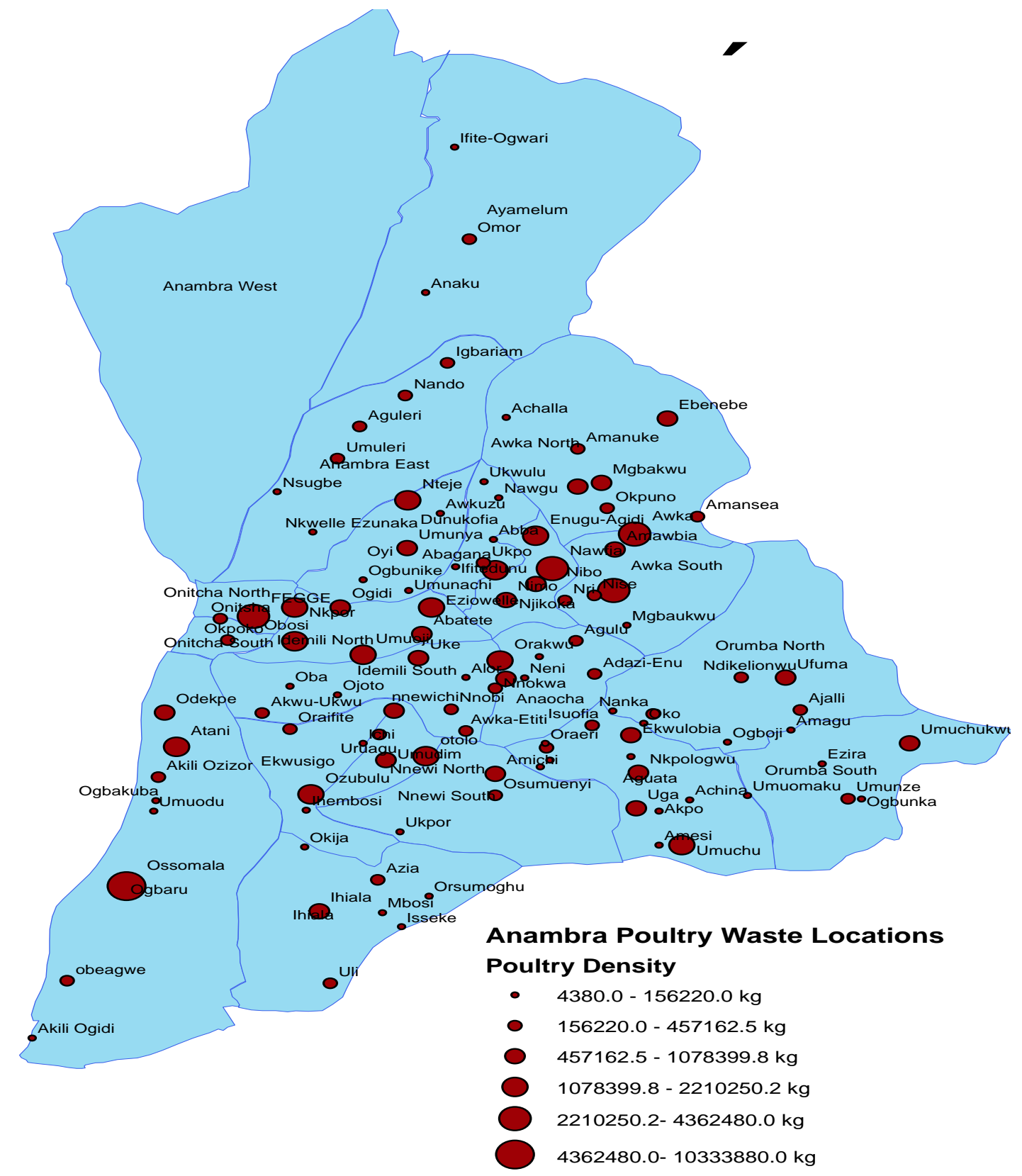

Figure 3: Poultry Production Spatial Density Map of the Study Area

\subsection{Spatial density analysis of biomass availability}

Density analysis of biomass availability takes known quantities of agricultural wastes obtained from field survey and spreads them across the landscape based on the quantity that is measured at each location and the spatial relationship of the locations of the measured quantities. Figure 3 shows the point density map of poultry production sites across the study area obtained using point density tool in spatial density toolbox in ArcGIS.

From the Figure above, the Ogbaru town has the highest point density which is above $4,362,480 \mathrm{~kg}$ value of poultry droppings. This is followed by Umuchu, Onitsha, Nise, Nibo and Amawbia, with point density that ranges from $2210250 \mathrm{~kg}$ to $4362480 \mathrm{~kg}$ value. The point density map also indicated clustering of medium and high point density of poultry production sites at the Central portion of the map. The Eastern and Western region of the study area also indicated clustering of medium and high point density poultry production in the study area. The North region of the study area shows dispersed low point density of poultry production. The clustering of poultry production sites at the Central, Eastern and Western region of the study area suggests that these regions will serve as candidate sites for bio-energy plant in the study area. 


\subsection{Spatial Distribution Analysis of Biomass Locations}

Hot spot analysis uses vectors to identify the locations of statistically significant hot spot and cold spot of poultry production sites. The analysis is focused on determining if high or low biomass resource centre are clustered. The result of the hotspot analysis is shown in Figure 4 below. From the Figure, several hotspots could be identified, majority of the hotspot lies in the central region of the study area, and of greater interest are the hotspots in the South west of the study area, where Umuodu, Ogbakuba and Ossomala were located. The Southern region of the study area is characterized with several cold spots indicating low poultry production sites, surround by low poultry production sites.

$\mathrm{A}$ high $\mathrm{Z}$ score and small $\mathrm{P}$ value for a feature indicates a significant hot spot. A low negative $\mathrm{Z}$ score and small $P$ value indicates a significant cold spot. The higher (or lower) the $\mathrm{Z}$ score, the more intense the clustering. A Z score near zero means no spatial clustering. A highlow clustering report was generated from the hotspot analysis. The report is as shown in Figure 5:

The observed General G is 0.106164 , while the $\mathrm{z}$ score is 0.089734 . The $p$-value is 0.928498 as shown in Figure 5 . The value of $z$ lies between -1.65 to 1.65 , the pattern therefore does not appear to be significantly different than random, thus generally, the poultry production sites in the study area is shown to be randomly distributed. Spatial autocorrelation test was further undertaken to see if the general pattern of features is clustered or dispersed (as opposed to clustering specifically of high or low values). The report generated is shown in Figure 6. Moran's index of 0.018522 was observed, $\mathrm{z}$ score of 0.96 indicates that there is no cluster of similar values. Since it is positive, there is an overall random pattern of biomass centres. It is also quite far from 1 , indicating the values are slightly clustered.

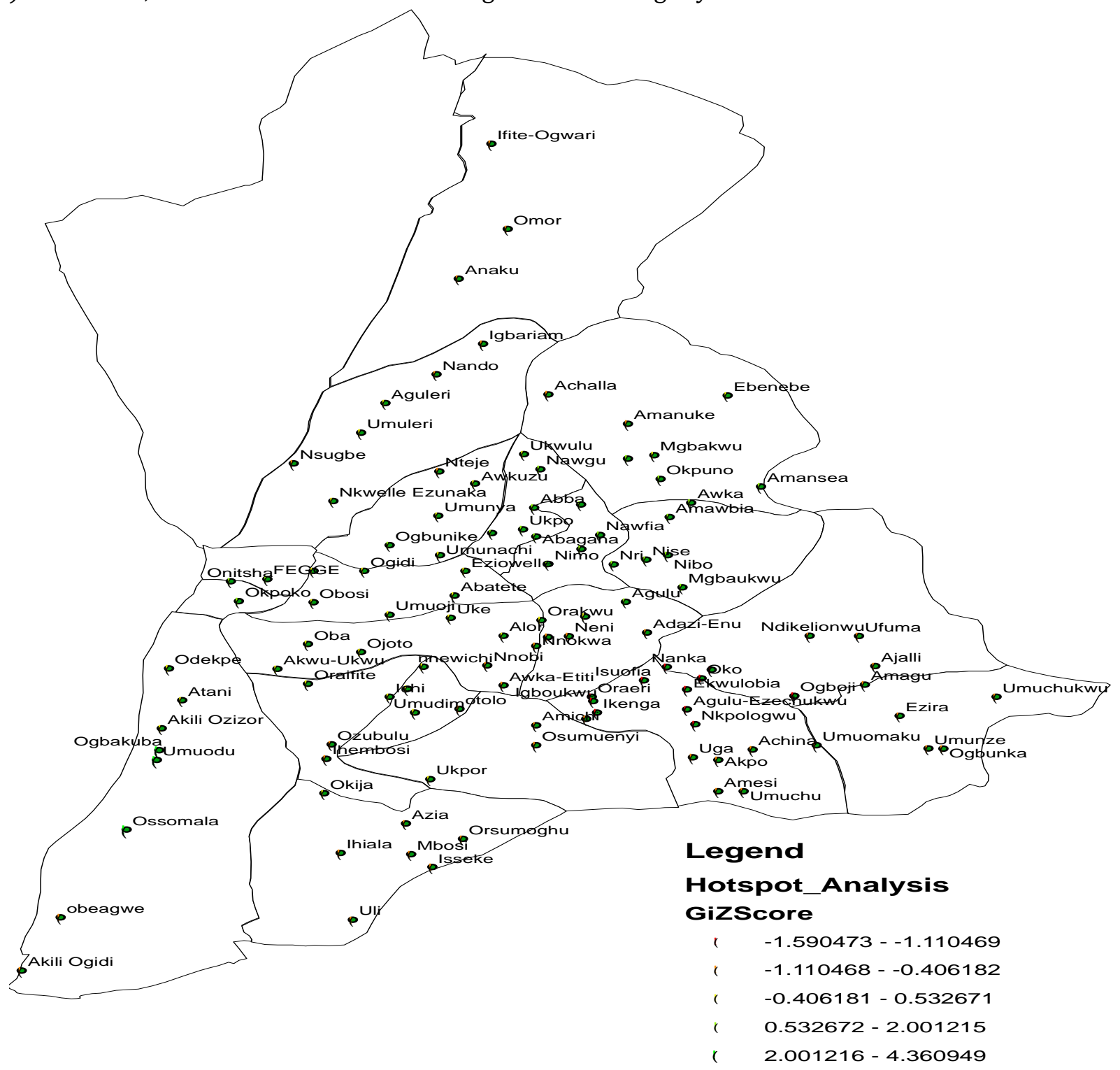

Figure 4: Hotspot Analysis of poultry production sites 


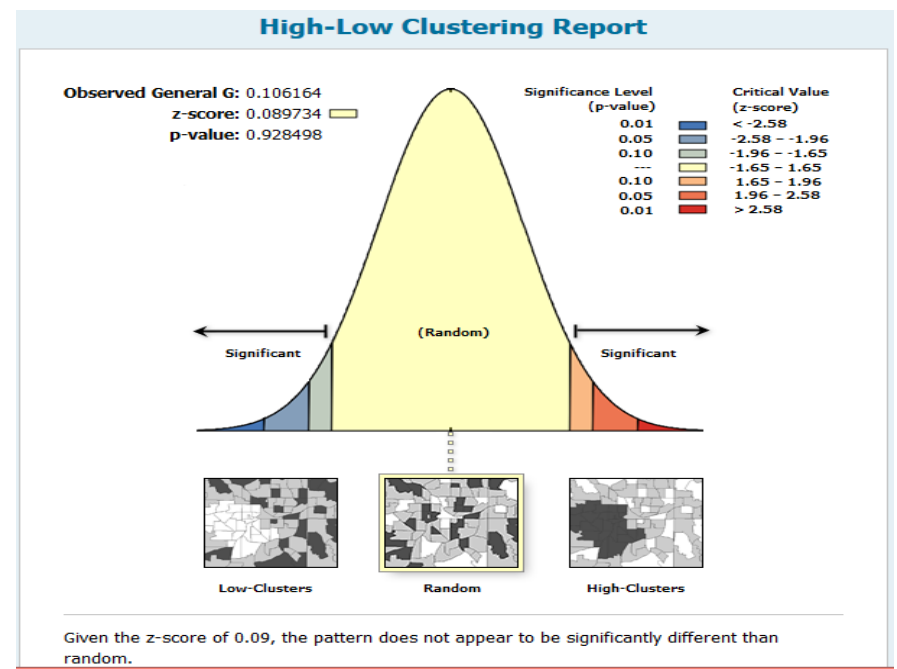

Figure 5: High-Low clustering report

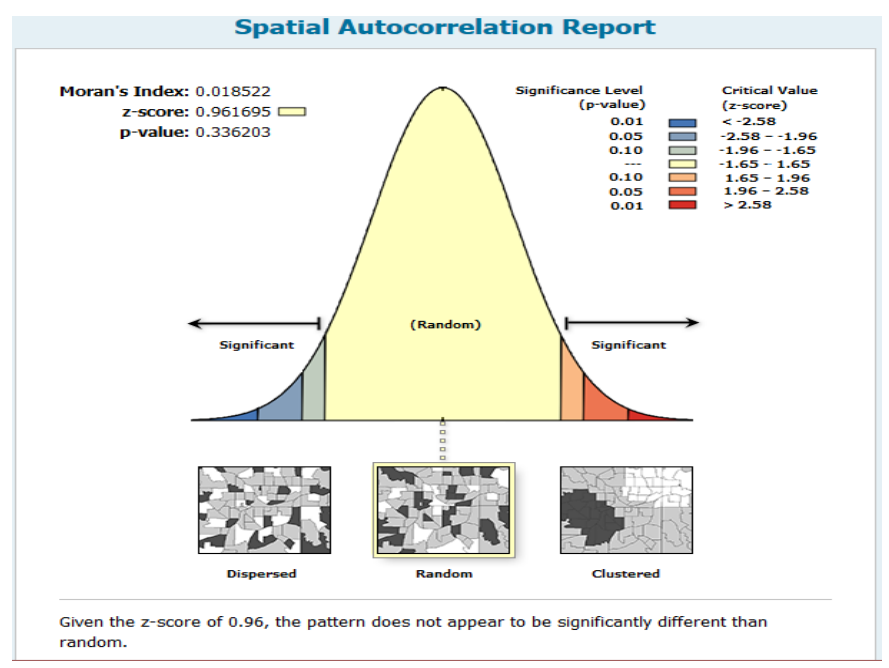

Figure 6: Spatial Autocorrelation Report

The auto-correction table report is presented below:

Table 2: Autocorrelation Index

\begin{tabular}{ll}
\hline General G Summary & Values \\
\hline Moran's Index: & 0.018522 \\
Expected Index: & -0.009009 \\
Variance: & 0.000820 \\
z-score: & 0.961695 \\
p-value: & 0.336203 \\
\hline
\end{tabular}

\section{CONCLUSION}

Spatial Statistics a method of analyzing spatial distributions, patterns, processes, and relationships was used in the analysis of poultry distribution in the study area. Maps generated are used as preliminary screening tools for policy and decision-making. The poultry production sites and production capacities were used to produce spatial density map of poultry production in the study area. The result indicated that the central regions of the state is characterised with high density poultry production sites. Also the hotspot analysis was used to identify high availability areas of agricultural resources in the study area. The result indicated that several hotspots lies in the central region of the study area, and in the South west of the study area, where Umuodu, Ogbakuba and Ossomala were located. The Southern region of the study area is characterized with several coldspots indicating low poultry production sites, surround by low poultry production sites. Hence, it can be inferred that conducting spatial relationships of biomass waste generation points prior to siting of bio-energy plants generally could result in improved location model performance.

\section{REFERENCES}

[1] Puks`ec, T., and Duic, N. Biogas potentials in Croatian farming sector, Strojarstvo 52:441-448. 2010.

[2] Pantaleo, A., Bernardo D., and Nilay, S. Assessment of optimal size of anaerobic co-digestion plants: An application to cattle farms in the province of Bari (Italy). Renewable and Sustainable Energy Reviews 20:57-70, 2013.

[3] Johnson, D. M., Zhang, F., and Sutherland, J. W., A GIS-based method for identifying the optimal location for a facility to convert forest biomass to bio-fuel. Biomass and Bioenergy, 35:3951-3961, 2011.

[4] Chukwuma, E. C. Chukwuma, G. O. Orakwe, L. C. An application of facility location models with hotspot analysis for optimal location of abattoir bio-energy plant in Anambra State of Nigeria. Inter. Jour. of Sc.\& Tech. Res. Vol. 5(4) 172-179. 2016.

[5] Höhn, J. E., Rasi, S., and Rintala, J., A Geographical Information System (GIS) based methodology for determination of potential biomasses and sites for biogas plants in Southern Finland. Applied Energy, 113, 1-10. 2014.

[6] Scott L, and Warmerdam N Extend crime analysis with ArcGIS spatial statistics tools. ArcUser Magazine, April-June [USA] 2005.

[7] Samson, M. Swaminathan, G. Venkat, K. N. Assessing groundwater quality for potability using a fuzzy logic and GIS - A case study of Tiruchirappalli city India. Computer Modelling and New Technologies, 14, (2) 58-68, 2010.

[8] Williams, C. M., Barker, J. C. and Sims, J. T. Management and utilization of poultry wastes; Tables 2, 3, 4, 5, 6 and 7.Rev. Environ. Contam. Toxicol., 162: 105-157. 1999.

[9] CMRC [Crime Mapping Research Center]. Crime Mapping Research Center "Hot Spot" Project. URL: 
http://www.ojp.usdoj.gov/cmrc/whatsnew/hotspo t/toc.html 1998.

[10] Moran, P.A.P. Notes on continuous stochastic phenomena, Biometrika 37, pp17-23. 1950.

[11] T U, J., \& Xia, Z. G. Examining spatially varying relationships between land use and water quality using geographically weighted regression I: model design and evaluation. Science of the Total Environment, 407, 358-378. 2008.
[12] ESRI, Understanding Spatial Statistics in ArcGIS 9. Downloaded on 12 $12^{\text {th }}$ May 2014 from http://www.utsa.edu/lrsg/teaching/ees6513/esri_ ws_spatialstatsslides.pdf. 2006.

[13] Levine, N. CrimeStat III: a spatial statistics program for the analysis of crime incident locations. Ned Levine \& Associates, Houston, TX., and the National Institute of Justice, Washington, DC. 2004.

APPENDIX

Table 1: Yearly bio-waste production capacity of towns and geographical coordinate point

\begin{tabular}{|c|c|c|c|c|c|c|c|c|c|c|}
\hline S/No & Towns & X Coord. & Y Coord. & Kg/year & S/No & Towns & $x$ & Coord. & Y Coord & Kg/year \\
\hline 1 & Achina & 7.12 & 5.96 & 87600 & 56 & Abatete & & 6.93 & 6.12 & 808110 \\
\hline 2 & Akpo & 7.10 & 5.95 & 17520 & 57 & Nkpor & & 6.83 & 6.15 & 1585122 \\
\hline 3 & Amesi & 7.10 & 5.92 & 156220 & 58 & Ogidi & & 6.87 & 6.15 & 714246.6 \\
\hline 4 & Ekwulobia & 7.08 & 6.02 & 547682.5 & 59 & Nnobi & & 6.95 & 6.05 & 271377.5 \\
\hline 5 & Nkpologwu & 7.08 & 5.99 & 567940 & 60 & Awka-Etiti & & 6.96 & 6.03 & 217467 \\
\hline 6 & Oraeri & 7.02 & 6.02 & 105120 & 61 & Oba & & 6.83 & 6.07 & 109135 \\
\hline 7 & Ifite-Ezinifite & 7.02 & 5.98 & 55480 & 62 & Akwu-Ukwu & & 6.81 & 6.05 & 179853.75 \\
\hline 8 & Agulu-Ezechukwu & 7.08 & 6.00 & 20075 & 63 & Ojoto & & 6.86 & 6.06 & 80537.25 \\
\hline 9 & Igboukwu & 7.02 & 6.01 & 281228.85 & 64 & Nnokwa & & 6.98 & 6.07 & 303315 \\
\hline 10 & Isuofia & 7.02 & 6.03 & 178120 & 65 & Alor & & 6.96 & 6.08 & 83402.5 \\
\hline 11 & Ikenga & 7.02 & 6.00 & 8760 & 66 & Azia & & 6.89 & 5.88 & 313699.25 \\
\hline 12 & Uga & 7.08 & 5.95 & 520855 & 67 & Ihiala & & 6.85 & 5.85 & 652985 \\
\hline 13 & Umuchu & 7.12 & 5.92 & 1620965 & 68 & Isseke & & 6.91 & 5.84 & 21900 \\
\hline 14 & Ogboji & 7.15 & 6.02 & 4380 & 69 & Mbosi & & 6.95 & 5.85 & 62050 \\
\hline 15 & Aguleri & 6.88 & 6.33 & 264077.5 & 70 & Okija & & 6.84 & 5.91 & 97820 \\
\hline 16 & Igbariam & 6.95 & 6.39 & 193723.75 & 71 & Orsumoghu & & 6.93 & 5.87 & 111836 \\
\hline 17 & Nando & 6.91 & 6.31 & 420206.25 & 72 & Uli & & 6.86 & 5.78 & 234968.75 \\
\hline 18 & Nsugbe & 6.82 & 6.26 & 150015 & 73 & Abagana & & 6.98 & 6.19 & 1349040 \\
\hline 19 & Umuleri & 6.86 & 6.30 & 225570 & 74 & Abba & & 6.98 & 6.22 & 13140 \\
\hline 20 & Adazi-Ani & 6.99 & 6.08 & 643677.5 & 75 & Enugu-Agidi & & 7.01 & 6.22 & 1624980 \\
\hline 21 & Adazi-Enu & 7.05 & 6.08 & 388871 & 76 & Enugu-Ukwu & & 7.01 & 6.17 & 1078399.8 \\
\hline 22 & Agulu & 7.04 & 6.12 & 417268 & 77 & Nawfia & & 7.02 & 6.19 & 4362480 \\
\hline 23 & Neni & 7.00 & 6.08 & 43800 & 78 & Nimo & & 6.99 & 6.16 & 705180 \\
\hline 24 & $\mathrm{Nri}$ & 7.03 & 6.16 & 205860 & 79 & Osumuenyi & & 6.98 & 5.97 & 210769.25 \\
\hline 25 & Adazi-Nnukwu & 7.01 & 6.10 & 13140 & 80 & Ukpor & & 6.91 & 5.93 & 67452 \\
\hline 26 & Achalla & 6.99 & 6.34 & 27740 & 81 & Amichi & & 6.98 & 5.99 & 618171.3 \\
\hline 27 & Amagu & 7.20 & 6.03 & 71769.95 & 82 & Nnewichi & & 6.91 & 6.05 & 955584.6 \\
\hline 28 & Amansea & 7.14 & 6.25 & 269643.75 & 83 & Uruagu & & 6.88 & 6.03 & 197680.35 \\
\hline 29 & Amanuke & 7.04 & 6.31 & 212630.75 & 84 & Umudim & & 6.90 & 6.00 & 575970 \\
\hline 30 & Isuanocha & 7.04 & 6.27 & 613200 & 85 & otolo & & 6.95 & 6.01 & 1835344.1 \\
\hline 31 & Mgbakwu & 7.06 & 6.27 & 634165.6 & 86 & AkiliOgidi & & 6.64 & 5.73 & 116800 \\
\hline 32 & Ebenebe & 7.13 & 6.34 & 628679.65 & 87 & AkiliOzizor & & 6.73 & 5.98 & 457162.5 \\
\hline 33 & Amawbia & 7.07 & 6.21 & 735840 & 88 & Atani & & 6.75 & 6.01 & 1170482 \\
\hline 34 & Nibo & 7.07 & 6.17 & 2784220 & 89 & Odekpe & & 6.74 & 6.05 & 912500 \\
\hline 35 & Okpuno & 7.06 & 6.25 & 226300 & 90 & Ogbakuba & & 6.73 & 5.96 & 78840 \\
\hline 36 & Awka & 7.08 & 6.22 & 2852110 & 91 & Okpoko & & 6.78 & 6.12 & 238162.5 \\
\hline 37 & Mgbaukwu & 7.08 & 6.13 & 131217.5 & 92 & obeagwe & & 6.67 & 5.78 & 248200 \\
\hline 38 & Nise & 7.05 & 6.16 & 265720 & 93 & Ossomala & & 6.71 & 5.88 & 10333880 \\
\hline 39 & Anaku & 6.93 & 6.46 & 16060 & 94 & Umuodu & & 6.73 & 5.95 & 102200 \\
\hline 40 & Omor & 6.96 & 6.51 & 189033.5 & 95 & Onitsha & & 6.78 & 6.14 & 342735 \\
\hline 41 & Ifite-Ogwari & 6.95 & 6.60 & 40077 & 96 & Fegge & & 6.80 & 6.14 & 2586371.8 \\
\hline 42 & Ukwulu & 6.97 & 6.27 & 13140 & 97 & Ajalli & & 7.20 & 6.05 & 350400 \\
\hline 43 & Ukpo & 6.97 & 6.19 & 272217 & 98 & Amaokpala & & 7.10 & 6.05 & 175200 \\
\hline
\end{tabular}




\begin{tabular}{ccccccccccc}
\hline S/No & Towns & X Coord. & Y Coord. & Kg/year & S/No & Towns & $X$ & Coord. & Y Coord & Kg/year \\
\hline 44 & Nawgu & 6.98 & 6.26 & 41756 & 99 & Nanka & 7.07 & 6.05 & 155490 \\
45 & Ifitedunu & 6.95 & 6.19 & 48180 & 100 & Ndikelionwu & 7.16 & 6.08 & 370110 \\
46 & Umunachi & 6.92 & 6.17 & 110266.5 & 101 & Oko & 7.09 & 6.04 & 75993 \\
47 & Ichi & 6.88 & 6.02 & 54987.25 & 102 & Ufuma & 7.19 & 6.08 & 554070 \\
48 & Ihembosi & 6.87 & 5.96 & 111763 & 103 & Ezira & 7.22 & 6.00 & 81030 \\
49 & Oraifite & 6.83 & 6.03 & 253821 & 104 & Ogbunka & 7.25 & 5.96 & 52560 \\
50 & Ozubulu & 6.85 & 5.96 & 1910935.6 & 105 & Umuchukwu & 7.28 & 6.02 & 584730 \\
51 & Eziowelle & 6.93 & 6.15 & 1276040 & 106 & Umunze & 7.24 & 5.96 & 360036 \\
52 & Obosi & 6.83 & 6.12 & 1397220 & 107 & Umuomaku & 7.16 & 5.97 & 48180 \\
53 & Orakwu & 6.98 & 6.10 & 1568916 & 108 & Umunya & 6.92 & 6.21 & 511000 \\
54 & Umuoji & 6.88 & 6.10 & 1441677 & 109 & Awkuzu & 6.94 & 6.24 & 119603.2 \\
55 & Uke & 6.92 & 6.10 & 643860 & 110 & Nteje & 6.92 & 6.26 & 2210250.2 \\
56 & Abatete & 6.93 & 6.12 & 808110 & 111 & NkwelleEzunaka & 6.84 & 6.21 & 43800 \\
57 & Nkpor & 6.83 & 6.15 & 1585122 & 112 & Ogbunike & 6.88 & 6.18 & 43800 \\
\hline
\end{tabular}

